\title{
Mind the gap \\ Stakeholders perspective on resilience building in the City of Rotterdam
}

Theresa Audrey O. ESTEBAN, Erasmus University Rotterdam, Graduate School of Social Science and the Humanities; The Philippines

\begin{abstract}
In 2016 the City of Rotterdam joined the 100 Resilient Cities of The Rockefeller Foundation. The 100 Resilient Cities is an initiative emphasizing the need for cities to build resilience. Rotterdam was one of the first to heed the call of the 100 Resilient Cities highlighting the city's position as a frontrunner in addressing climate adaptive urban planning projects and innovative means in dealing with flood risks and vulnerabilities. Learning from the great North Sea flood of 1953 disaster experience, the Netherlands ensured strong preventive measures making the country safe from flooding. The City of Rotterdam benefits from these strong preventive measures as this safeguards the city and the biggest and most important port in Europe from any disaster. However, these strong preventive measure have also muted the concept of resilience on the stakeholders. This is also further weighed down by the many different initiatives present in the city. The paper seeks to investigate the institutional and non-institutional actors perspective on resilience and the environmental threats in the City of Rotterdam. The research assumes that knowledge and experience on Rotterdam's environmental vulnerabilities and threats lead to better collaboration between and among stakeholders in making the city resilient. This knowledge and experience also leads to the mutual adaptation of roles between the government and other stakeholders of the city such as the citizens, businesses, academe, civil society organizations among others. The research explores questions related to stakeholders perception on risk and vulnerability of the city to disasters, disaster awareness and concern, and their definition of resilience and a resilient city.
\end{abstract}

\section{Keywords}

Resilience, Resilient city, Collective engagement, Flood risk, Netherlands

\section{Introduction}

One of the most significant flooding disaster that occurred in the Netherlands is the 1953 North Sea Flood. The flood which hit the South of Holland on 01 February 1953 'breached approximately $180 \mathrm{kms}$ of coastal-defense dikes' (Watson and Finkl, 1990: 740). This inundated 160,000 hectares of polderland and left a total of 1,835 dead (Watson and Finkl, 1990: 740). The North Sea Flood disaster impacted the way the Dutch managed flood risk, stressing that the great flood of 1953 should never happen again.

Five years after the Great North Sea Flood the Dutch carried out the Delta Plan prioritizing the implementation of the Deltaworks project which is composed of a network of dams, sluices, 
storm surge barriers throughout the multi-river delta created by the Rhine, Meuse and Scheldt located in the South of Holland. The project entailed the strengthening of dikes in Holandsche Ijssel and construction of advance engineering design and technology for the coastal and flood defense such as the Maestlankering storm surge barrier. The project called for raising existing dikes, storm closure of main tidal estuaries and inlets, except the waterway link between Rotterdam and Antwerp to give access to both ports as such dikes in those areas were strengthened (Watson and Finkl, 1990; Wesselink, 2007). This extensive and elaborate flood defense system have successfully safeguarded the country and cities like Rotterdam from any impending flood risk.

However, in 1993 and 1995 the feeling of safety and security was challenged when an extreme high river discharge in the Meuse and Rhine rivers happened (Lu and Stead, 2013; Wesselink, 2007). This has prompted the Dutch to rethink their relationship with water by proposing a more adaptive strategy, Room for the River, to allow more space for water. The threat of changing climatic condition have increased the vulnerability of delta cities to rising sea levels and extreme water discharge in rivers to the sea. The City of Rotterdam has been active in addressing these issues through the various plans, programs and projects around the city. The review of planning and policy documents from 2004 to 2010 conducted by Lu and Stead (2013) showed impacts of climate-related flood risks and vulnerabilities existed since the mid-2000s. The study related this to the concept of resilience in Rotterdam's spatial planning and policymaking where they found that in the city the notion of resilience is considered by local planners as a term of enhancing the city's image, and promoting development in places outside the protective dikes and as a synonym for adaptation (Lu and Stead, 2013). The term resilience then covers different ideas among policy-makers and technocrats alike and remains an abstract concept for many stakeholders.

In 2013 the Rockefeller Foundation launched the 100 Resilient City initiative to help more cities build resilience to physical, social and economic challenges that are a growing part of the 21st century (The Rockefeller Foundation, 2017). Cities under this initiative are provided access to resilience-building tools and services supplied by a carefully selected platform partners from the private, public, academic, and non-profit sectors. The City of Rotterdam was one of the first to apply to the program and in 2016 released its Resilience Strategy targeting a $100 \%$ climate proof city by 2025 . The Strategy likewise drew attention to engagement and collaboration of the stakeholders in meeting its action plans. While this initiative is not the first to spearhead resilience programming in the city it is the only initiative that highlight Rotterdam as a "resilient city". Many stakeholders however remain oblivious to the meaning of "resilience".

In this light, this paper assumes that knowledge and experience on Rotterdam's environmental vulnerabilities and threats lead to better collaboration between and among stakeholders in making the city resilient. This knowledge and experience also leads to the mutual adaptation of roles between the government and other stakeholders of the city such as the citizens, businesses, academe, civil society organizations among others. The paper focuses on awareness as an important thematic area being investigated by the author in her dissertation research. It explores questions related to stakeholders perception on the city's risk and vulnerability to disasters, awareness, concern and response to disasters, and their definition of resilience and a resilient city.

Following this introduction, the paper proceeds with a review of the definition of resilience and the varying conception of resilience. Then the concept of collective engagement urban 
resilience framework as a conceptual tool explaining the complexity of resilience building in the urban context will be introduced. The framework likewise identifies two approaches in urban resilience and the main actors involved which is imperative in the methodology of the empirical study. Thereafter primary data gathered from the face-to-face interviews of the various stakeholders of the City of Rotterdam will be discussed. Finally, the research findings and discussions will be outlined including its implication to future research.

\section{Different perspectives of resilience}

Originally a concept used in ecology, resilience was first defined by C.S. Holling as a "measure of the persistence of systems and their ability to absorb change and disturbance and still maintain the same relationships between populations or state variables" (Holling, 1973: 14). He later redefined this as the magnitude of the disturbance that can be absorbed before a system changes its structure by changing the variables and processes that control behavior (Holling, et al., 1997; Mayunga, 1995; Berry, 2013). In this second definition, resilience is understood as the capacity of a system to absorb disturbance and maintain its equilibrium. This ecological perspective of resilience means that the system has an ability to cope with disturbances and return to its functioning state. It assumes that a system undergoes multiple levels of equilibrium but still retain its structure and function (Gunderson, 2010; Mehmood, 2015; Wagner, et al., 2014; Sharifi and Yamagata, 2016; Holling, 1973; Folke, 2006). Holling asserted that resilience should be interpreted as having multiple-equilibria rather than seen as a single-equilibrium (Holling, et al., 1997; Sharifi and Yamagata, 2016). While Elmqvist (2014) offered to extend the resilience concept by stating that resilience is not just recovering from a single disturbance but also refers to the capacity of a system to adapt and transform.

Apart from the earlier mentioned ecological perspective of resilience there are different perspectives on the term resilience. Engineering resilience which interprets resilience to having a single-equilibrium where a system bounces back to its pre-disaster phase after a disaster (Gunderson and Holling, 2002; Andavarapu and Arefi, 2016). This implies that 'equilibrium' or stability only refers to reverting to the pre-disaster phase through recovery (Gall, 2013). Engineering resilience assumes that disturbances or disasters are predictable and forecasting methods are reliable sources of information (Sharifi and Yamagata, 2016).

The socio-ecological resilience perspective recognizes that systems have multiple equilibria facilitating the systems' ability to absorb and adapt to disturbances. This resilience perspective interprets resilience as having multi-equilibrium where the system has the capacity to reorganize and transform to another state (equilibrium) after a disturbance. Socio-ecological resilience is also known as adaptive resilience which stemmed from recognizing cities as complex and dynamic socio-ecological systems (Sharifi and Yamagata, 2016). Two other perspectives on resilience following the multi-equilibrium interpretation are social resilience and community resilience. Social resilience is the ability of groups or communities to cope with external stresses and disturbances as a result of social, political, and environmental change (Adger, 2000). Most of the work on social resilience were based on prevention, preparation and response to natural disasters and the management of natural resources (Keck and Sakdapolrak, 2013; Takeuchi et al., 2014; Mehmood, 2015). While community resilience refers to the ability of the community to bounce back using its own resources. This terminology is often used in disaster management work specifically in rebuilding and reconstruction. 
The resilience concept assumes the dynamic and complex adaptive systems across temporal and spatial scales (Folke, 2006). It is a multidisciplinary concept that explores persistence, recovery, and the adaptive transformative capacities of interlinked social and ecological systems and subsystems Elmqvist (2014: 5). The different perspectives of resilience magnify its multidisciplinary and complex nature.

\section{Transformation, adaptability and resilience building}

The terms adaptability and transformation are key in creating resilient cities. Adaptability refers to the ability of the stakeholders to influence resilience (Folke, et al., 2010). It is the 'collective capacity of the human actors in the socio-ecological system to manage resilience' (Walker, et al., 2004: 7). Transformation, on the other hand, is the ability of the system to shift from its current normal state to another development or improved state (Sharifi and Yamagata, 2016). Transformation is necessary in building resilience through spatial and temporal scales. Transformation, similar to adaptation, requires an understanding of the roles each stakeholders contribute to the city's overall function. It is the result of the improvements done during the adaptation process

The city is a complex, multidimensional socio-ecological system that continuously undergo changes. Disasters such as flooding elicit these changes and adds on to a city's already complex behavior. The city's collective engagement to address these changes at various levels and scales determines its ability to become resilient. One key element in building resilience are the stakeholders, particularly their capacity, awareness, and understanding of resilience in order for them to collectively take part in building resilience. But in order for stakeholders to participate in building resilience there is a need to expand their knowledge and awareness. This knowledge does not only focus on how to build resilience but also why it is needed. The awareness and concern on risks and vulnerabilities of the city are important to bring this into focus.

There are two sides in approaching urban resilience, one the approach taken by the government and the other by the citizens. These two approaches interlace into what collective engagement is all about. That is "a collaborative process participated in by multiple stakeholders to arrive at a solution or decision to increase urban resilience through both formal and informal means" (Esteban, 2018). This means that both approaches of the government and the citizens should be on the same level. Obviously the technical, technological, and scientific interpretations cannot be equal between the government and the citizens but there should be a leveled understanding on what resilience is. Understanding resilience and building urban resilience requires public concern and awareness.

The collective engagement urban resilience framework (Figure 1) incorporated the two approaches into a conceptual framework that emphasizes that the government and the citizen (self-organization) approach to urban resilience can be two different ways. Both still go through the same four dimensions of collective engagement - concern, action, efficacy and security - in order to reach resilience. This can be assessed in terms of the collaborative capacities of the institutional actors (government) and the non-institutional actors (citizens and citizen groups). It meets in the middle when both actors increase their capacities and collaboration to achieve their common goal of building resilience (mutual adaptation of roles). 
The framework looks at the two approaches and in so doing understand the different perspectives on resilience and how both lead to the common denominator which is concern for their city. In the succeeding section, the methodology for the empirical study will be outlined.

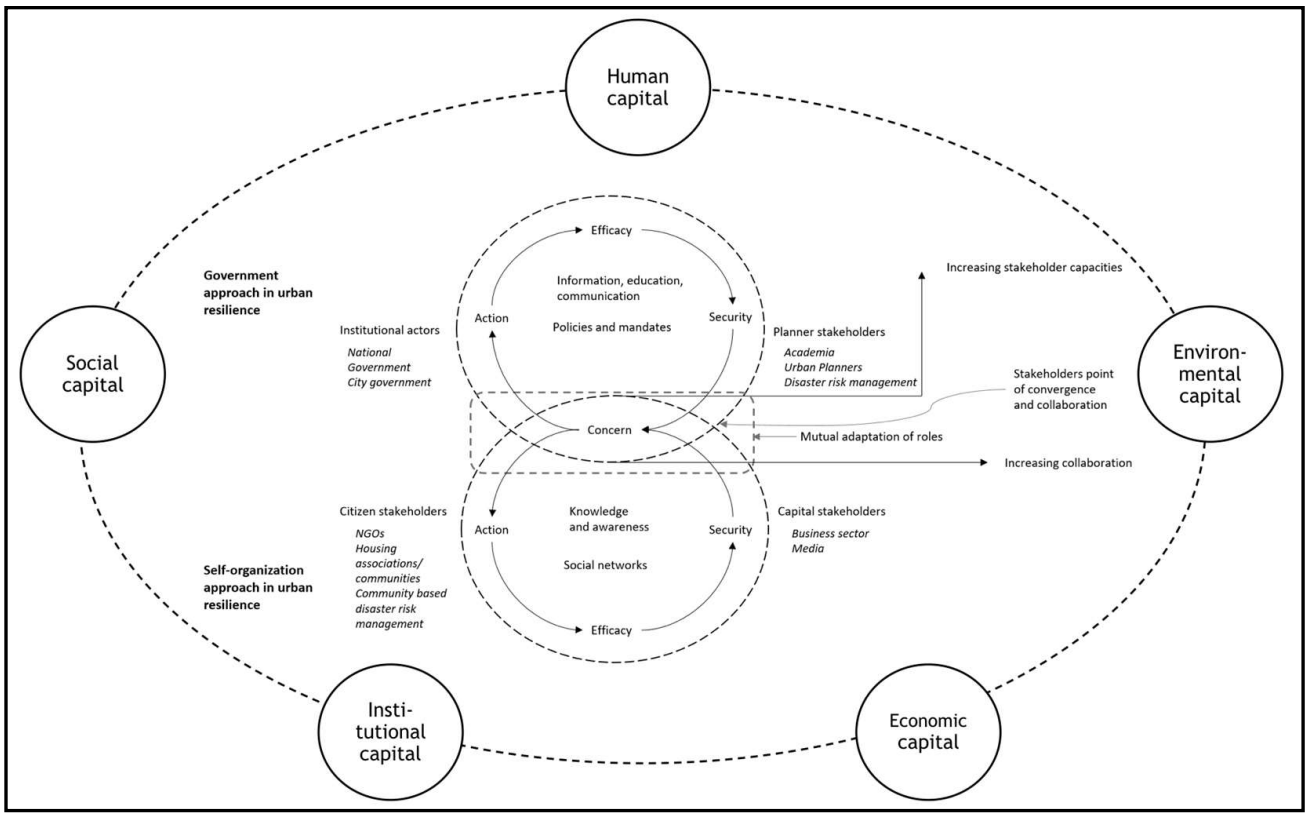

Figure 1 Collective engagement urban resilience framework (Source: Author, 2018)

\subsection{Methodology}

This paper is based on the initial findings of the author's fieldwork under the thematic areas awareness, key threats and resilience for the dissertation project 'Collective engagement: from disaster-prone city to disaster-resilient city'. These thematic areas are three of the ten thematic areas in the semi-structured interview guide used in the fieldwork done from November 2018 to February 2019.

Using the concept of the collective engagement urban resilience framework, the paper focused on the stakeholders involved in the government and the self-organization approach to urban resilience. The government stakeholders identified for the study are the institutional actors (government workers and the water board) and the planners (academics). Under the self-organization approach stakeholders identified are citizens (non-government organizations, community council, housing associations, private citizens) and the capital stakeholders (architectural firm and the port authority). Key informant interviews were conducted using a semi-structured interview guide containing open-ended questions on perception on risks and vulnerabilities in the city, awareness and concern of the general population on flood risks, and definition of resilience and resilient city.

\subsection{Sampling Methodology}

The key informant interviews targeted key knowledgeable persons in city development and planning, and disaster risk management in the City of Rotterdam. An initial list of 10 persons were identified (5 institutional, 1 planner, 2 citizens, and 2 capital stakeholders) using the snowball sampling each responded were asked to recommend one to two persons to be 
interviewed until a target of at least 13 respondents were reached. In total 19 interviews were done for the case study ( 9 institutional, 2 planners, 6 citizens and 2 capital stakeholders).

\subsection{Processing}

The qualitative data gathered through the interviews were transcribed, collated, reviewed and processed using the Atlasti software. Based on the main line of inquiry: (1) awareness and concern on flood risks, (2) perception of risk and vulnerabilities, and (3) definition and perception of resilience, the qualitative data were allocated general codes, i.e. disaster experience, awareness, resilience with subsequent sub-codes at it emerged in the review. Memoing was done as insights arose.

\section{Primary key findings}

The results of the key informants interview were categorized into the three main line of inquiries: (1) awareness and concern on flood risks, (2) perception of risk and vulnerabilities, and (3) definition and perception of resilience. Memoing was done as insights rose from the interviews.

\subsection{Awareness and concern to flood risks}

There is a general perception among the interviewees on the low level of awareness of the stakeholders in Rotterdam on flood risks and vulnerabilities. Most of the interviewees asserted that people feel safe and secure in terms of flooding. One interviewee even pointed out the low level of awareness in the country because "disasters always happen somewhere else, you see it on tv but not in your neighborhood" (Citizen stakeholder, male), while another wondered on the awareness of people that they live below sea level (Citizen stakeholder, female).

The big issue in the Netherlands is that people are unaware of the threats . . . in the Netherlands we have no disasters, we have no floods, so people are not aware but in fact we are very vulnerable. (Planner stakeholder, male)

I wonder how many people really feel that they live below sea level because we didn't have any disasters. The only disaster we have is our bank account because we have to pay for that every year we receive an amount and we have to pay it. (Citizen stakeholder, female)

Most of the interviewees attribute the low level of awareness and concern on the risks due to the high safety and preventive measures of the Netherlands (Planner stakeholder, male (2); Institutional stakeholder, male (6); Institutional stakeholder, female (3); Citizen stakeholder, female; Citizen stakeholder, male (2); Capital stakeholder, male (2)). Many of the interviewees often quoted the probability ' 1 in 10,000 years' of a flood disaster in the country which gives security to the general population (Planner stakeholder, male (2); Capital stakeholder, male; Citizen stakeholder, male; Institutional stakeholder, male). One asserted that the 1953 flooding disaster happened so long ago that,

The new generation is used to the fact that it is arranged that okay nothing bad happened so far [ ] when the Delta program was built they felt safe. So this whole new generation they never had anything to do with it. You see what I mean? So it's not in their psyche, it's not in their minds that they should be afraid of anything. (Planner stakeholder, male)

Some of the interviewees say that there is a level of awareness among the people but it varies (Planner stakeholder, male; Institutional stakeholder, male; Citizen stakeholder, male; Capital 
stakeholder). An interviewee asserted that the Dutch are aware because they learn it from school and everybody knows about the Delta Works (Planner stakeholder, male). Interviewees mentioned that people have an idea on threats because they can see it on the television but the idea of this happening in the future is not present nor do they know what to do about it (Institutional stakeholder, female (2); Citizen stakeholder, male (2); Capital stakeholder, male; Institutional stakeholder, male).

I think most Dutch are aware because they learn it in school, and of course everybody knows about the Delta Works and the Maesland barrier, but I think most people don't know about that website where you know how the elevation of your residence whether you are below sea level. So I think they are not aware of the urgency and also not so much on the threats. (Planner stakeholder, male)

Interviewees pointed out that a certain level of awareness is present for people who live in areas where it usually gets flooded and/or where most people have a higher level of education and income (Institutional stakeholder, female (3); Planner stakeholder, male (2); Institutional stakeholder, male (3); Citizen stakeholder, male; Capital stakeholder, male). Many of the interviewees identified the Nordereiland as the only place where most people are aware of flooding and know what to do when there is a flood (Institutional stakeholder, female (3); Planner stakeholder, male; Institutional stakeholder, male (2); Citizen stakeholder, male (3)). The location of the residents of Rotterdam also has to do with the socio-economic and educational status. Interviewees from the institutional actors mentioned that people living in the north have a higher education and higher income compared to the south. In these cases interviewees view that there are other concerns that stakeholders feel are more important than thinking about flooding (Institutional stakeholder, female (2); Planner stakeholder, male; Citizen stakeholder, male (2); Citizen stakeholder, female; Capital stakeholder, male).

So I would say in terms of awareness I would say there is a difference. But maybe also secondly if your main concern is how to make it through the month, then maybe that is actually what you are really aimed at and not so much actually about the other stuff. (Capital stakeholder, male).

\subsection{Perceived key threats}

The perceived threats of the interviewees vary from environmental threats to social threats. Environmental threats can be classified as having too much water and too little water. Interviewees who fall under the categories of institutional actors and planners stakeholders identified flooding coming from four directions of water 'from the river, from the sea, from rain and groundwater'. There is also a problem on too little water especially during the summer periods. Too little water according to the interviewees affects the wooden piles where most old houses are built on since it rots. Interviewees also mentioned that too little water also affects the strength of the polders.

It's the flooding because I always say water comes from four [sides] here. You have water from the river, from the sea, from rain, and also groundwater is coming up. So in four ways the water is coming. (Institutional stakeholder, male)

We have in our street a simple association and they come together one or two times a year but here in this street the problem is the opposite, the water level in the ground is too low. And for that reason the wooden piles under the old houses, they only stay intact when they are below water, wooden pile stays intact when they are below water levels. And when the water 
levels get more down the top of the piles they get rotten so when you walk on the street you see at the moment they are working on the foundations. So the opposite problem. The water level is too low in the ground. The ground water is too low. (Citizen stakeholder, male)

Social related threats have also cropped up in the interview as a bigger threat than the risk of flooding. Several interviewees mentioned that 'there are so many nationalities living' in Rotterdam (Institutional stakeholder, female; Citizen stakeholder, male) and not a lot of people have high education due to people working in the harbor (Institutional stakeholder, female; Institutional stakeholder, male). Some see the big social and economic gap that one interviewee said,

If you have that in your world you cannot really focus on energy transition and sustainability, stuff like that. I think there is too big of a gap between those people and those people who can actually look forward because they are privileged in that kind of sense. (Institutional stakeholder, female)

This social and economic gap is also seen by one interviewee that hinders people from 'joining society' (Institutional stakeholder, female). The same interviewee also mentioned that there is an aging population in Rotterdam where most are concentrated in the south.

\subsection{Perception and definition of resilience}

The interviewees were asked to define resilience and describe what a resilient city is. Interviewees with a more technical background defined resilience in terms of their technical knowledge, referring to 'a system is able to bounce back in the state it was before' (Institutional stakeholder, female; Planner stakeholder, male (2); Citizen stakeholder, male (2); Institutional stakeholder, male (2)). Some referred to concepts of the Rockefeller Foundation.

I have always in my mind the definition of Rockefeller Foundation about urban resilience as a way to handle shocks and stresses in the best way. . . So we work, the Rockefeller Foundation had sort of a definition and also all kinds of resilience qualities, like robustness, flexibility, redundancy, integration. (Institutional stakeholder, male)

While one interviewee defined it holistically.

When I make a definition of a resilient city and that is also for the whole town planning. It is strong as it is complex. When it is simple, it is also simple to destroy. So the whole network of the city has to be not only one or two or three but ten different layers of mentality, of physical structures, of maintenance of the city, of all the those things, make it to a strong environment. (Citizen stakeholder, male)

While some also asserted that 'it should bounce back into a system where it has a higher level of resilience than it had before' (Planner stakeholder, male; Institutional stakeholder, male). Some interviewees also found the term 'resilience' as abstract (Citizen stakeholder, male) preferring other terms as robustness, preparedness, flexibility, or simply using the Dutch word 'veerkracht' (Institutional stakeholder female; Capital stakeholder, male; Institutional stakeholder, male; Citizen stakeholder, male). Some interviewees defined resilience and resilient city with a social orientation (Citizen stakeholder, male (2); Citizen stakeholder, female; Institutional stakeholder, female). The interviewees view the ability of the people to connect with each other as a way to make the city resilient. 
When asked what factors contribute to making a resilient city, interviewees found social and institutional factors as the most important (Institutional stakeholder, female (3); Planner stakeholder, male; Institutional stakeholder, male (2); Citizen stakeholder, male (3); Citizen stakeholder, female; Capital stakeholder, male). Interviewees identified strong social networks, working together with the community and awareness as important to bring this idea of resilience (Institutional stakeholder, female (3); Planner stakeholder, male; Institutional stakeholder, male (2); Citizen stakeholder, male (3); Citizen stakeholder, female; Capital stakeholder, male). Some also pointed out to the ability to maintain this resilience through ensuring that there is a budget for maintenance and not just implementation (Citizen stakeholder, male; Citizen stakeholder, female). While some mainly point out the importance of people in general as factor in resilience.

But resilient city is all technical things but it also has to do with the people who live here, we all have to bring that up, we have to pay for it. It can only be done by the people who are themselves are one, aware of it, and two, they have to have the money and the knowledge. So the city can only be flexible if people want to pay for it and people can work together. It's the only way. So it starts at the bottom with people who are willing to cooperate. (Citizen stakeholder, female)

Well, I think that people in disaster context they rely on their networks. And there are a lot of examples in Rotterdam where there are stronger communities that people know their neighbors, that they work together, that they do workshops, that they cook together and those ties are very important within a disaster context. I also know that there are certain areas that people don't know their neighbors, that they are very distant from each other and I think that will be a problem whenever there is a disaster if you don't know where to go or where to search for help. I mean then you are by yourself and in a disaster context you always need other people. (Institutional stakeholder, female)

How Rotterdam is, I think. Rotterdam is a city that was bombed in the war. My father was living in the area where it was bombed in the war. Then my father and his brother and their mother, the three of them the house was gone and they went to live in the West in a house without anything, they started to build a new life. And many people did in Rotterdam, and the immigrants came from everywhere and they had nothing. Now [there are] many [ ] they started to work very hard in the harbor. That is resilience. Incredible, you know. So we are a very resilient city. It is really incredible how people survived the war and started with nothing and people came from everywhere and with nothing and they have a house and many children and grandchildren. Incredible. Sometimes they are sick because of the work, and they built their own life. That is resilience. People. (Citizen stakeholder, male)

\section{Analysis and conclusion}

The results of the interview indicate that the stakeholders see that there is a level of awareness on flood risk in Rotterdam. This level of awareness can be attributed to Dutch history lessons which is part of the educational curriculum. Since the 1953 Great North Sea Flood and Deltaworks project is part and parcel of the Dutch history this is also discussed in school. This means that there is a general understanding on the history of the Dutch way of managing water and preventing disasters. However, from the time of the 1953 flood the rarity of any disaster occurring have affected the level of awareness of the stakeholders specifically on flood risk. This time and experiential gap between 1953 and the present time have made 
the population least concerned about flood risk. This is also exacerbated by a growing generation gap among the population who never witnessed the 1953 flooding or have ever experienced any type of flooding.

Interviewees with a more technical background recognize the vulnerability of the city to disasters including the possibility of a disaster from happening. However, this is not often translated to the non-technical stakeholders or the laymen. The government has instilled the feeling of safety and security among the citizens with the repetitive mention of risk being 1 in 10,000 years, a number calculated by scientists and engineers on the possibility of another disaster such as the 1953 flooding ever happening. In fact, most if not everyone knows the ratio ' 1 in 10,000 years' in the Netherlands but many people do not realize that the 1 in that ratio is a possibility that can happen anytime - today, tomorrow, next week or in the 10,000th year. Many interpret this as happening not in their lifetime. This perhaps is the second gap that can be recognized in the study.

In Rotterdam most of the people aware of the flood risk are those who live in Nordereiland which is outside the dike. Residents in Nordereiland are most of the time subjected to flooding during the storm season. This brings up the question whether awareness and concern on the risks of flooding depends on the location. It was raised by the interviewees that while location can be a contributing factor in the level of awareness of the stakeholders, as in the case of Nordereiland, it is also mainly due to the type of community existing in terms of social and economic status. People with lower income will be more concerned about their daily living expenses than the possibility of flooding or more so climate change. Those with higher income and higher education have a wider network in the city, pay higher income tax, and may have a stronger stance on government and/or political issues that may affect them and their community. This social and economic gap among the city stakeholders is also seen as a threat by the interviewees because it impedes on the ability of those belonging in the lower income from integrating in the city. Esteban (2017) noted strong stakeholders tied to the community as one of the contributing factors in collective engagement and rapid recovery after a disaster. Relating this to resilience building, citizens who do not fit into a community nor the city will have a much more difficult time seeing themselves as part of the city. Integration is important in resilience building because this makes citizens feel that they are connected to the city, that they are valued, and that they can contribute to its growth.

A fourth gap that can be seen from the interview is the way stakeholders define resilience. Stakeholders defined resilience in two perspectives, one is more technical attributing resilience to the city's physical make up. It is how the city is planned to adapt to the changing climatic conditions as well as ensure that the city can bounce back from any disaster. The strong preventive measures play a role in making the city resilient. Interviewees see the importance of continuous improvement of these preventive measures to incorporate climate change adaptation as a factor in creating a resilient city. This suggests a more structural, engineering, and spatial design element. The other perspective is mainly focused on the social aspect of resilience, in particular the role of the people of Rotterdam. The interviewees see that the people and their social networks are equally important to create a resilient city.

The last gap that can be drawn from the interviews is the translation of the word 'resilience' itself. Some interviewees perceive resilience as an abstract concept. The concept of resilience and resilient city is still lost in translation for some of the interviewees including some institutional actors who would rather use words such as robustness, preparedness and flexibility. The Dutch term veerkracht is more acceptable for many interviewees since it hits 
the local language. In this way, it can be said that the acceptability of the concept of resilience may be better achieved if it is relatable, such as using the local language to draw the general population towards the vision of the city.

The collective engagement urban resilience framework shows that the mutual adaptation of roles of all stakeholders help in building resilience. If the level of awareness and concern on disasters, risks and vulnerabilities is low among the stakeholders, how then will stakeholders engage to address these risks and vulnerabilities. The gap between strong preventive measures and preparatory measures can be narrowed down by raising awareness on flood risk management, climate change adaptation, and resilience building. It will also help to make the concept of resilience more identifiable to all stakeholders. The goal is not exactly to make a unified definition of resilience and a resilient city but a definition that is more engaging.

\section{Acknowledgements}

I would like to thank the interviewees from the City of Rotterdam for their willingness to be interviewed and their honesty in sharing their views. I am especially thankful to my PhD promotor Dr. Jurian Edelenbos of the Erasmus University Rotterdam who has supported me from the beginning of my PhD journey, provided extensive feedback on my dissertation project, and continues to guide me in the direction that would most help me succeed.

\section{References}

Adger, William Niel (2000) "Social and ecological resilience: are they related?", Progress in Human Geography, Vol. 24, No. 3 (September).

Andavarapu, Deepika; Arefi, Mahyar (2016) "Understanding resilience in urban slums: Lessons from Pedda-Jalaripeta, India", plaNext, Vol. 2, (April).

Berry, Melissa M. (2013) "Thinking like a city: Grounding social-ecological resilience in an urban land ethic", Idaho Law Review, Vol. 50, pp. 117-152.

Elmqvist, Thomas (2014) "On urban social-ecological systems, sustainability and resilience implications for SDGs and development of indicators", International Council for Science.

Esteban, Theresa Audrey O. (2018) Building resilience through collective engagement, paper presented at the conference Constructing an urban future: The sustainability and resilience of cities, Abu Dhabi, United Arab Emirates, March 18-19, 2018 edn.

Folke, Carl (2006) "Resilience: The emergence of a perspective for social-ecological systems analyses", Global Environmental Change, Vol. 16, No. 3, (August).

Folke, Carl; Carpenter, Stephen R; Walker, Brian; Scheffer, Marten; Chapin, Terry; Rockstrom, Johan (2010) "Resilience thinking: integrating resilience, adaptability and transformability", Ecology and Society, Vol. 15, No. 4, (December).

Gall, Melanie (2013) From social vulnerability to resilience: measuring progress toward disaster risk reduction, No. 13/2013 edn, UNU-EHS, Germany.

Gunderson, Lance (2010) "Ecological and human community resilience in response to natural disasters", Ecology and Society, Vol. 15, No. 2 (June). 
Gunderson, Lance H.; Holling, Crawford Stanley (2002) Panarchy: understanding transformations in human and natural systems, Island Press, USA.

Heintze, Hans-Joachim; Kirch, Lotte;Kuppers, Barabara; Mann, Holger; Mischo, Frank; Mucke, Peter; Pazdzierny, Tanja; Prutz, Ruben; Radtke, Katrin; Strube, Friederike; Weller, Daniel; (2018) World Risk Report 2018, Bundnis Entwicklung Hilft and Ruhr University Bochum - Institute for International Law of Peace and Armed Conflict, Germany.

Holling, Crawford Stanley (1973) "Resilience and stability of ecological systems", Annual Review of Ecology and Systematics, Vol. 4, No. 1 (November)

Holling, Crawford Stanley; Schindler, David W.; Walker, Brian W.; Roughgarden, Jonathan; (1997) "Biodiversity in the functioning of ecosystems: an ecological synthesis" in Biodiversity loss: Economic and ecological issues, eds. C. Perrings, K. Mäler, C. Folke, C.S. Holling \& B. Jansson, Cambridge University Press, Cambridge, pp. 44-83.

Keck, Markus; Sakdapolrak, Patrick; (2013) "What is social resilience? Lessons learned and ways forward", Erdkunde, Vol. 67, No. 1 (January)

Lu, Peiwen; Stead, Dominic; (2013) "Understanding the notion of resilience in spatial planning: A case study of Rotterdam, The Netherlands", Cities, Vol. 35 (December)

Marcus, Lars (2008) "Spatial Capital and how to measure it", New urbanism and beyond (January).

Marcus, Lars; Colding, Johan (2011) "Towards a spatial morphology of urban socialecological systems", 18th International Seminar on Urban Form Montreal, 26-29 (August)

Mayunga, Joseph S. (2007) "Understanding and applying the concept of community disaster resilience: a capital-based approach", Summer academy for social vulnerability and resilience building, Vol. 1 (July)

Mehmood, Abid (2015) "Of resilient places: planning for urban resilience", European Planning Studies, Vol. 24, No. 2 (September)

Sharifi, Ayyoob; Yamagata, Yoshiki; (2016) "Principles and criteria for assessing urban energy resilience: A literature review", Renewable and Sustainable Energy Reviews, Vol. 60 (July)

Takeuchi, Kazuhiko; Elmqvist, Thomas; Hatakeyama, M; Kauffman, Joanne; Turner, Nicholas; Zhou, Dingyang (2014) "Using sustainability science to analyse social-ecological restoration in NE Japan after the great earthquake and tsunami of 2011", Sustainability science, Vol. 9, No. 4 (October)

The Rockefeller Foundation (2017) 100 Resilient cities. Available: https://www.rockefellerfoundation.org/our-work/initiatives/100-resilient-cities/

Wagner, Melissa; Chhetri, Netra; Sturm, Melanie (2014) "Adaptive capacity in light of Hurricane Sandy: The need for policy engagement", Applied Geography, Vol. 50 (June) 
Walker, Brian; Holling, Crawford Stanley; Carpenter, Stephen; Kinzig, Ann (2004) "Resilience, adaptability and transformability in social-ecological systems", Ecology and Society, Vol. 9, No. 2 (December)

Watson, lan; Finkl Jr, Charles W (1990) "State of the art in storm-surge protection: The Netherlands Delta Project", Journal of Coastal Research (Summer)

Wesselink, Anna J. (2007) "Flood safety in the Netherlands: the Dutch response to Hurricane Katrina", Technology in Society, Vol. 29, No. 2 (April) 